\title{
Review of impingements around the hip joint
}

\author{
Jae Hwan Lim', Kang Yeol Koํ․ Suenghwan $\mathrm{Jo}^{2}$ \\ Department of Orthopedic Surgery, ${ }^{1}$ Suwan Hospital, ${ }^{2}$ Chosun University Hosptial, Gwangju, Korea
}

Received September 15, 2021

Accepted September 28, 2021

Corresponding author

Suenghwan Jo

Department of Orthopedic Surgery,

Chosun University, School of

Medicine, 365 Pilmundae-ro,

Dong-gu, Gwangju 61453, Korea

Tel: +82-62-220-3147

Fax: +82-62-226-3379

E-mail: jo.suenghwan@chosun.ac.kr

ORCID:

https://orcid.org/0000-0001-7262-

$710 \mathrm{X}$

\begin{abstract}
Hip pain in athletes is relatively common but is often underdiagnosed. Historically, surgery has been utilized only for hips with osteoarthritis or osteonecrosis, and pain from other causes was considered to be self-limiting. However, recent studies have reported that surgical treatment may benefit patients with recalcitrant pain that is derived from impingement around the hip. The current review aims to describe the common impingement syndromes around the hip joint which can be a cause of pain, as well as detrimental to function. The review also highlights surgical methods that have recently been developed for treating such impingements.
\end{abstract}

Keywords: Femoroacetabular impingement; Subspine impingement; Ischiofemoral impingement; Pelvitrochanteric impingement

\section{FEMOROACETABULAR IMPINGEMENT}

Femoroacetabular impingement (FAI) has been studied for decades . In 1936, Smith-Peterson conducted a study of pistol grip deformity in the femoral head causing abutment and pain, and defined FAI as abnormal impingement of the proximal femur against the acetabulum [1]. In general, FAI is subdivided into cam and pincer types. However, a great majority of patients may show evidence of both cam and pincer simultaneously; this referred to as a 'mixed' or 'combined' type [2]. The cam type FAI is characterized by a bump in the femoral head-neck junction and is most commonly found in the anterosuperior quadrant [3]. The resultant shear force from the cam deformity may cause labrum tearing and cartilage damage. Cam-type FAI is reported to be more common in young male athletes [4]. The pincer type FAI is characterized by acetabular over-coverage on the femoral head that results in pinching of the labrum. This type can be more common found in middle-aged female athletes [4]. Mixed type FAI is reported to be present in up to $90 \%$ of symptomatic patients [5,6].

Historically, the operation for FAI was performed using open resection of the bony bump and excision of the labrum $[7,8]$. However, since Ganz et al. validated the importance of recovering the suction sealing mechanism, the operative treatment on the labrum has evolved from resection to restoration [Q]. The current repair methods for the labrum focus on creating function seal mechanisms; thus, restoring labrum shape is paramount $[10,11]$.

The loop around repair technique is one of the most commonly used repair methods for secure labrum refixation. However, this method may cause labrum bunching, resulting in disruption of the native triangular cross-sectional anatomy. In addition, there is a possibility of the labrum 
being everted away from the femoral head, which may result in irreproducibility of the normal contact between the labrum and the femoral head. The vertical mattress suture has also been proposed as a repair method, but the penetration of the labrum by the suturing instrument may disrupt the labrum which will result in loss of the suction seal mechanism. A newer technique involves the fixation of only the labral base. Labral base repair recreates the triangular shape of the native labrum and also prevents the labrum from everting away from the joint resulting in recreation of the sucion seal mechanism. However, it is technically demanding procedure. The operative methods for cam and pincer lesions are shown in Figs. 1 and 2.

\section{ISCHIOFEMORAL IMPINGEMENT}

Ishciofemoral impingement (IFI) is a frequently unrecognized cause of hip pain; it is derived from direct abutment
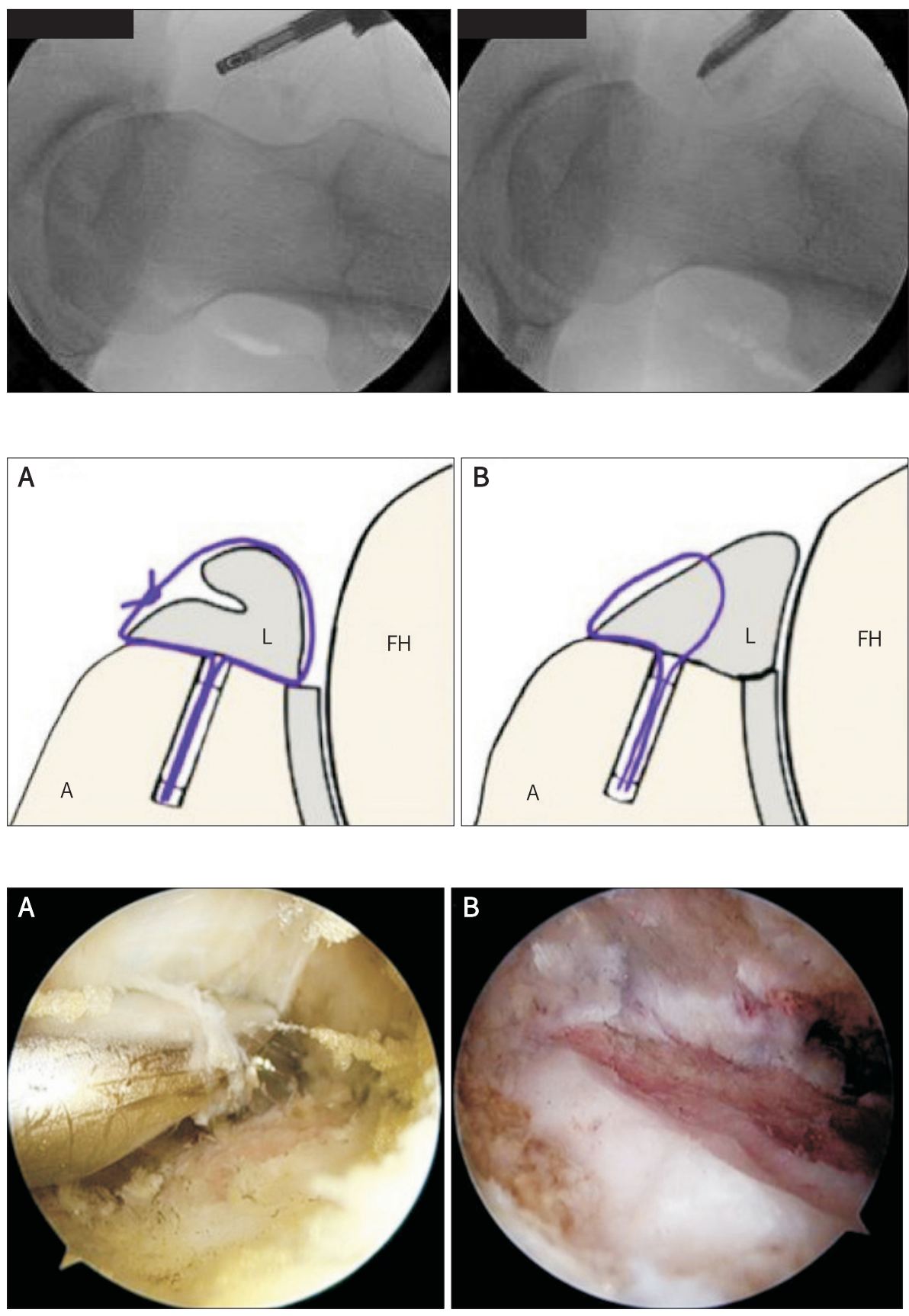

Fig. 1. Resection of the cam lesion under microscopy. Note the femur is in Dunn lateral view to visualize the anterolateral quadrant of the femoral head.

Fig. 2. Labral repair technique. (A) looped repair, (B) vertical mattress repair.

Fig. 3. (A) Resection of lesser trochanter to treat IFI, (B) post-resection. IFI: ishciofemoral impingement. 
between the lesser trochanter (LT) and the ischium, or from compression or entrapment of the quadratus femoris muscle between the two structures [12]. Originally described in 1977 from iatrogenic conditions after total hip arthroplasty [13], such impingement is now recognized to also occur naturally. The condition may improve with non-operative treatment, but surgery may be required in cases with recalcitrant symptoms. There are only a few literatural documentation of surgical techniques for IFI, and these mostly recommend excision of the LT through an open approach. However, with the recent improvements in arthroscopic techniques and devices, the entire LT can now be accessed endoscopically.

The operation utilizes proximal and distal lateral portals and, seldomly, accessory portals. The lesser trochanter can be visualized at the attachment of the iliopsoas tendon. The goal of the operation is to enlarge the ischiofemoral space, which should be approximately $23 \mathrm{~mm}$ (Fig. 3). The use of a curved burr and positioning of the hip in external rotation are necessary to access and resect the lesser trochanter appropriately.

\section{ANTERIOR INFERIOR ILIAC SPINE IMPINGEMENT}

Anterior inferior iliac spine (AIIS), impingement, or subspine impingement, is a type of extra-articular impingement and another potential cause of inguinal pain. This condition is one of the common reasons for pain in young athletes since it most frequently occurs as a consequence of AIIS avulsion injury. The first description of AIIS impingement was in 2008, and it was defined as an abutment between enlarged or elongated AIIS against the femoral head [14]. Symptoms are identical to those of FAI, which is prominent in hip flexion injuries, but local tenderness often accompanies AIIS. Computed tomography scans can create three-dimensional reconstructions that demonstrate three types of AIIS: Type I, in which there is a smooth ilium wall between the most caudad level of the AIIS and the anterosuperior rim; Type II, in which the AIIS prominence extends to the level or above the acetabular rim; and Type III, in which the AIIS extends distally to the acetabular rim (Fig. 4) [15].

Traditionally, AIIS impingement has been approached via an open intervention [14,16,17]. However, recent studies reports excellent short-term outcomes following arthroscopic decompression, which is performed just proximal to the anterior rim $[6,18,19]$. However, it should be noted that overresection may result in detachment of the rectus femoris muscle; thus, the procedure should be conducted with caution [6].

\section{PELVITROCHANTERIC IMPINGEMENT}

Pelvic-greater trochanter type impingement, or pelvitrochanteric impingement, is another type of impingement that may result in pain. This type is often seen in patients who have history of Legg-Calve-Perthes disease, slipped capital femoral epiphysis (SCFE), or congenital dislocation [20]. These preexisting diseases can result in a shortened femoral neck and a greater trochanter in a more prominant and proximal position (Fig. 5). Pain typically occurs during walking or other types of hip abduction due to abutment between the ilium and greater trochanter [21]. This may also result in abductor weakness and decreased range of motion.

Since 1969, when the first operative treatment was described by Jani et al., various surgical options have been
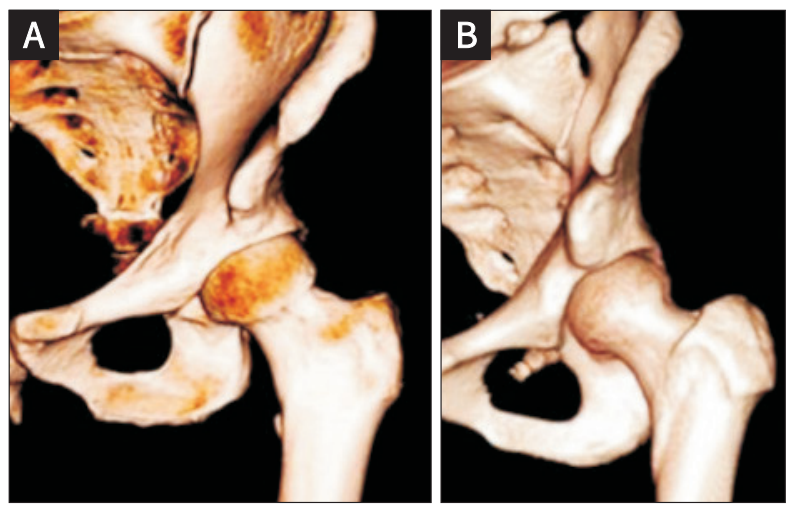

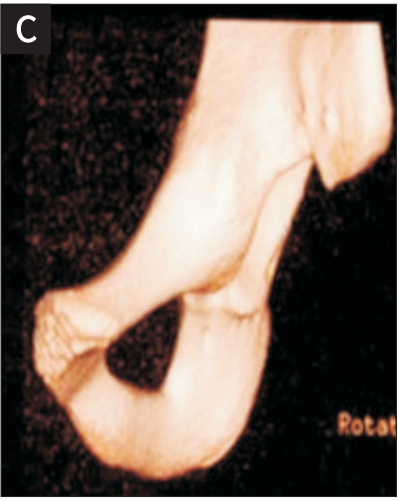

Rots
Fig. 4. Types of AllS impingement. (A) Type I, (B) type II, (C) type III. AllS: anterior inferior iliac spine. 


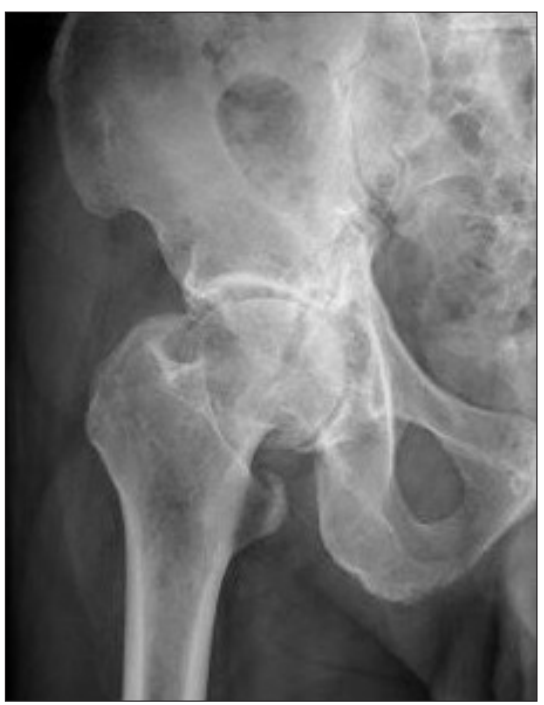

Fig. 5. Right hip of a 45-year-old man with pelvitrochanteric impingement and accompanying acetabular fracture. Note the high-riding trochanter and short femoral neck.

introduced. These include lateralizing or distal osteotomy of the greater trochanter, femoral head reduction osteotomies, and osteochondroplasty [22,23].

\section{SUMMARY}

Impingements around the hip joint are potential causes of hip pain during sports, but are often challenging to diagnose. A thorough patient history and physical examination, along with a proper radiologic exam, are paramount to making an accurate diagnosis. Effort should be made to recognize less common types of hip impingements, as operation may be necessary for recalcitrant cases in order to enable timely return to sport activities.

\section{CONFLICT OF INTEREST}

No potential conflict of interest relevant to this article was reported.

\section{REFERENCES}

1. Smith-Petersen MN. Treatment of malum coxae senilis, old slipped upper femoral epiphysis, intrapelvic protrusion of the acetabulum, and coxa plana by means of acetabuloplasty. J Bone Joint Surg Am 1936;18:869-80.

2. Ganz R, Bamert P, Hausner P, Isler B, Vrevc F. [Cervico-ac- etabular impingement after femoral neck fracture]. Unfallchirurg 1991;94:172-5. German.

3. Pfirrmann CW, Mengiardi B, Dora C, Kalberer F, Zanetti M, Hodler J. Cam and pincer femoroacetabular impingement: characteristic MR arthrographic findings in 50 patients. Radiology 2006;240:778-85.

4. Crawford JR, Villar RN. Current concepts in the management of femoroacetabular impingement. J Bone Joint Surg Br 2005;87:1459-62.

5. Beck M, Kalhor M, Leunig M, Ganz R. Hip morphology influences the pattern of damage to the acetabular cartilage: femoroacetabular impingement as a cause of early osteoarthritis of the hip. J Bone Joint Surg Br 2005;87:1012-8.

6. Hapa O, Bedi A, Gursan O, Akar MS, Güvencer M, Havitçioğlu $\mathrm{H}$, et al. Anatomic footprint of the direct head of the rectus femoris origin: cadaveric study and clinical series of hips after arthroscopic anterior inferior iliac spine/subspine decompression. Arthroscopy 2013;29:1932-40.

7. Botser IB, Smith TW Jr, Nasser R, Domb BG. Open surgical dislocation versus arthroscopy for femoroacetabular impingement: a comparison of clinical outcomes. Arthroscopy 2011;27:270-8.

8. Sampson TG. Arthroscopic treatment of femoroacetabular impingement. Tech Orthop 2005;20:56-62.

9. Leunig M, Beaulé PE, Ganz R. The concept of femoroacetabular impingement: current status and future perspectives. Clin Orthop Relat Res 2009;467:616-22.

10. Espinosa N, Rothenfluh DA, Beck M, Ganz R, Leunig M. Treatment of femoro-acetabular impingement: preliminary results of labral refixation. J Bone Joint Surg Am 2006;88:92535.

11. May O, Ouattara K, Flecher X, Wettstein M; Francophone Arthroscopy Society (SFA). Does labral repair have a clinical benefit during arthroscopic treatment of femoro-acetabular impingement? Prospective multicentre study with 2-year follow-up. Orthop Traumatol Surg Res 2020;106:S237-41.

12. Torriani M, Souto SC, Thomas BJ, Ouellette H, Bredella MA. Ischiofemoral impingement syndrome: an entity with hip pain and abnormalities of the quadratus femoris muscle. AJR Am J Roentgenol 2009;193:186-90.

13. Johnson KA. Impingement of the lesser trochanter on the ischial ramus after total hip arthroplasty. Report of three cases. J Bone Joint Surg Am 1977;59:268-9.

14. Pan H, Kawanabe K, Akiyama H, Goto K, Onishi E, Nakamura $\mathrm{T}$. Operative treatment of hip impingement caused by hypertrophy of the anterior inferior iliac spine. J Bone Joint Surg Br 2008;90:677-9.

15. Carton P, Filan D. Anterior inferior iliac spine (AIIS) and subspine hip impingement. Muscles Ligaments Tendons J 2016;6:324-36. 
16. Irving $\mathrm{MH}$. Exostosis formation after traumatic avulsion of the anterior inferior iliac spine. Report of two cases. J Bone Joint Surg Br 1964;46:720-2.

17. Rajasekhar C, Kumar KS, Bhamra MS. Avulsion fractures of the anterior inferior iliac spine: the case for surgical intervention. Int Orthop 2001;24:364-5.

18. Amar E, Druckmann I, Flusser G, Safran MR, Salai M, Rath E. The anterior inferior iliac spine: size, position, and location. An anthropometric and sex survey. Arthroscopy 2013;29:87481.

19. Hetsroni I, Larson CM, Dela Torre K, Zbeda RM, Magennis E, Kelly BT. Anterior inferior iliac spine deformity as an extra-articular source for hip impingement: a series of 10 patients treated with arthroscopic decompression. Arthroscopy 2012;28:1644-53.
20. Macnicol MF, Makris D. Distal transfer of the greater trochanter. J Bone Joint Surg Br 1991;73:838-41.

21. Albers CE, Steppacher SD, Schwab JM, Tannast M, Siebenrock KA. Relative femoral neck lengthening improves pain and hip function in proximal femoral deformities with a high-riding trochanter. Clin Orthop Relat Res 2015;473:137887.

22. Anderson LA, Erickson JA, Severson EP, Peters CL. Sequelae of Perthes disease: treatment with surgical hip dislocation and relative femoral neck lengthening. J Pediatr Orthop 2010;30:758-66.

23. Shore BJ, Novais EN, Millis MB, Kim YJ. Low early failure rates using a surgical dislocation approach in healed LeggCalvé-Perthes disease. Clin Orthop Relat Res 2012;470:24419. 